\title{
EXTRAÇÕES DE ÓLEO DA POLPA DE ABACATE (Persea americana MILL) UTILIZANDO DIFERENTES SOLVENTES
}

\author{
OIL EXTRACTIONS OF ABACATE PULP (Persea americana MILL) USING \\ DIFFERENT SOLVENTS
}

\author{
A. P. OLIVEIRA ${ }^{1}$; E. G. T. MENEZES ${ }^{1}$ \\ ${ }^{1}$ Instituto de Ciências Agrárias. Universidade Federal de Viçosa - Campus Rio Paranaíba \\ E-mail: amanda.p.oliveira@ufv.br
}

\author{
$\underline{\text { a r t i c le info }}$ \\ Article history: \\ Received 12 May 2017 \\ Accepted 3 August 2017 \\ Available online 20 September 2017
}

PALAVRAS-CHAVE: Abacate; Extração; Solventes, Óleo.

KEYWORDS: Avocado; Extraction; Solvents, Oil.

\begin{abstract}
RESUMO: $O$ abacate (Persea americana Mill) é um fruto originado do continente Americano, amplamente produzido no território brasileiro. A sua polpa carnuda proporciona a extração de um óleo de alta qualidade, contendo vários compostos bioativos. Neste trabalho, avaliou-se a viabilidade de extração do óleo de abacate, utilizando diferentes condições de extração. A polpa do abacate foi seca em estufa, e posteriormente moída para a obtenção de um farelo. As extrações foram realizadas com $3 \mathrm{~g}$ da amostra e quantidades variáveis de solvente (etanol, hexano, isopropanol e acetona) para obter diferentes razões sólido:solvente (1:5, 1:7,5 e 1:10). O sistema foi incubado em Shaker, a temperatura constante $\left(35^{\circ} \mathrm{C}, 45^{\circ} \mathrm{C}\right.$ e $\left.55^{\circ} \mathrm{C}\right)$, sob agitação de $120 \mathrm{rpm}$ durante 24 horas. Após esse tempo, uma amostra da fase extrato foi retirada, com microsseringa. A concentração total de solvente foi determinada por meio de evaporação até massa constante a $60^{\circ} \mathrm{C}$, e então foram calculados os rendimentos de extração de sólidos solúveis presentes nas polpas de abacate expressos em $g$ de óleo/g de polpa seca. Os resultados demonstraram que o aumento da diluição de solvente e da temperatura, aumentaram a proporção de extração. Na diluição $1: 10$ a $55^{\circ} \mathrm{C}$, todos os solventes apresentaram semelhantes extrações e na proporção $1: 5$ a $35^{\circ} \mathrm{C}$ o etanol apresentou baixo rendimento. Os resultados mostram que o etanol pode ser utilizado como solvente alternativo na extração de óleos vegetais.
\end{abstract}

\begin{abstract}
Avocado (Persea americana Mill) is a fruit originated from the American continent, widely produced in Brazilian territory. Its fleshy pulp provides the extraction of a high quality oil containing several bioactive compounds. In this work, the viability of avocado oil extraction was evaluated using different extraction conditions. The avocado pulp was dried in an oven, and then milled to obtain a bran. Extractions were performed with $3 \mathrm{~g}$ of the sample and varying amounts of solvent (ethanol, hexane, isopropanol and acetone) to obtain different solid: solvent ratios (1: 5, 1: 7.5 and 1:10). The system was incubated in Shaker at constant temperature $\left(35^{\circ} \mathrm{C}, 45^{\circ} \mathrm{C}\right.$ and $\left.55^{\circ} \mathrm{C}\right)$ under shaking at $120 \mathrm{rpm}$ for 24 hours. After that time, a sample of the extract phase was withdrawn, with microsyringe. The total solvent concentration was determined by evaporation to constant mass at $60 \mathrm{oC}$, and then the extraction yields of soluble solids present in the avocado pulps expressed in $\mathrm{g}$ oil/g dry pulp were calculated. The results demonstrated that increased solvent dilution and temperature increased the extraction rate. At the 1:10 dilution at $55 \mathrm{oC}$, all solvents showed similar extractions and in the ratio 1:5 at 35 oC ethanol showed poor yield. The results show that ethanol can be used as an alternative solvent in the extraction of vegetable oils.
\end{abstract}




\section{The Journal of Engineering and Exact Sciences - \\ JCEC \\ ISSN: 2527-1075}

\section{INTRODUÇÃ̃}

O abacate (Persea americana Mill) é um fruto originado do continente Americano, amplamente produzido no território brasileiro. Apresenta um grande número de variedades, incluindo Fortuna, Quintal, Geada, Margarida e Hass (JORGE et al., 2015). Seu cultivo é considerado um dos mais produtivos por unidade de área cultivada (Tango e Turatti, 1992).

A polpa carnuda do abacate proporciona um óleo de alta qualidade com grandes níveis de ácido oléico, e com propriedades físico-químicas semelhantes às do azeite de oliva (TANGO; CARVALHO; SOARES, 2004). Além disso, o óleo de abacate apresenta diversos compostos bioativos, incluindo carotenoides, ácido ascórbico, compostos fenólicos, tocoferóis, fitoesterois, entre outros (SANTOS et al., 2014). A extração com solvente é o método mais realizado industrialmente e normalmente apresenta maiores rendimentos de extrações e produz um óleo menos turvo (LIAUW et al., 2008). O solvente hexano é o mais utilizado atualmente para a extração desses óleos vegetais, devido às suas vantagens como baixa temperatura de ebulição $\left(69^{\circ} \mathrm{C}\right)$, elevada estabilidade, baixa corrosão, baixo resíduo nas tortas e elevada capacidade de dissolver o óleo (BAKER, 1983). Contudo, também, há desvantagens associadas, principalmente, em relação a questões ambientais, de segurança operacional e de saúde (DAGOSTIN; CARPINE; CORAZZA, 2015). Devido a esses problemas, ao longo dos anos, tem-se estudado a substituição do hexano por outros solventes.

Entre os solventes alternativos, encontram-se álcoois de cadeia curta, principalmente, o etanol e isopropanol, que têm como vantagens maior segurança ambiental e à saúde e menor probabilidade de ocorrência de problemas operacionais (RODRIGUES; ARACAVA; ABREU, 2010).

O etanol é um solvente promissor para extração de óleos vegetais porque o Brasil produz uma grande quantidade a partir da cana de açúcar, além de apresentar baixa toxicidade e ser menos inflamável que o hexano. Face à sua natureza polar, o etanol é um solubilizante mais fraco de triacilgliceróis que o hexano e é capaz de solubilizar outros componentes presentes na célula como água e compostos bioativos (DAGOSTIN et al., 2015). A solubilidade dos óleos vegetais em etanol é dependente da temperatura e do conteúdo de água presente no solvente (OLIVEIRA et al., 2012).

O isopropanol pode ser produzido a partir do petróleo e de fontes renováveis. A extração com isopropanol produz óleo de alta qualidade contendo elevadas quantidades de tocoferóis e compostos fenólicos, além de ser mais seguro e menos tóxico do que o hexano (GANDHI et al., 2003).

Outro solvente bastante utilizado é a acetona, cujas características de solubilidade são semelhantes às dos álcoois, sendo estes interessantes substitutos do hexano, além de possuir calor latente de vaporização inferior ao do isopropanol (TIR; DUTTA; AHMED, 2012).

O presente estudo teve como objetivo avaliar a viabilidade de extração de óleos e compostos bioativos utilizando diferentes condições de extração em batelada. 


\section{The Journal of Engineering and Exact Sciences - \\ JCEC \\ ISSN: 2527-1075}

\section{MATERIAL E MÉTODOS}

Foram utilizados abacates (Persea americana Mill) obtidos no município de Rio Paranaíba-MG. Inicialmente os frutos maduros foram higienizados (solução de hipoclorito, $200 \mathrm{mg} / \mathrm{kg}$ ) e despolpados manualmente. As polpas, então, foram armazenadas congeladas ($18{ }^{\circ} \mathrm{C}$ ) até o momento do seu uso. Antes dos processos de extraç̃os, as polpas foram secas em estufa a vácuo sob temperatura de $60{ }^{\circ} \mathrm{C}$, durante $48 \mathrm{~h}$. Posteriormente, as mesmas foram trituradas em liquidificador industrial (Camargo, Itajobi, SP, Brasil).

Processos de extração

As extrações foram realizadas em erlenmeyer de vidro de $125 \mathrm{~mL}$, os frascos foram tampados com rolhas de borracha para evitar a perda do solvente. Para cada tratamento foram utilizados $3 \mathrm{~g}$ de amostra de polpa de abacate seca e quantidades variáveis de solvente (etanol, hexano, isopropanol e acetona) para obter as seguintes razões sólido:solvente (RSL) 1:5 m/m, $1: 7,5 \mathrm{~m} / \mathrm{m}$ e $1: 10 \mathrm{~m} / \mathrm{m}$. O sistema foi incubado (Shaker Luca-222, Lucadema, São José do Rio Preto, SP, Brasil), a temperatura constante $\left(35^{\circ} \mathrm{C}, 45^{\circ} \mathrm{C}\right.$ e $\left.55^{\circ} \mathrm{C}\right)$, sob agitação de 120 rpm durante $24 \mathrm{~h}$ (tempo suficiente para estabelecer o equilíbrio). As massas utilizadas das polpas moídas e dos solventes foram pesadas em uma balança analítica com uma capacidade de leitura de $0,0001 \mathrm{~g}$. Todos os tratamentos foram realizados em duplicata.

Atingido o tempo de extração, uma amostra da fase extrato foi retirada, utilizando microsseringa conectada ao septo, tomando-se cuidado para não modificar a temperatura do sistema. A concentração total de solvente foi determinada por meio de evaporação até massa constante a $60^{\circ} \mathrm{C}$ em estufa. Por esse procedimento, pôde-se determinar a fração mássica do solvente, na fase extrato ( $\mathrm{w}_{\mathrm{solFE}}$ ), bem como a fração mássica de óleo na mesma fase, designado por (WóleofE).

Através das frações determinadas foi calculado para cada tratamento a quantidade de óleo extraído para cada g de polpa seca utilizada, de acordo com a equação 1.

$$
R_{i}(\text { g de óleo/g de polpa })=\left(\frac{\mathrm{w}_{\text {oleoFE }} \mathrm{M}_{\mathrm{FE}}}{\mathrm{M}_{\mathrm{polpa}}}\right)
$$

Em que:

$\mathrm{M}_{\text {polpa: }}$ massa de polpa utilizada na extração.

$\mathrm{M}_{\mathrm{FE}}$ : massa da fase extrato.

\section{RESULTADOS E DISCUSSÃO}

A Tabela 1 apresenta os resultados obtidos nas extrações, através destes podemos observar o efeito do aumento da temperatura e diluição. 


\section{The Journal of Engineering and Exact Sciences - \\ JCEC \\ ISSN: 2527-1075}

Tabela 1 - Rendimentos de extrações de sólidos solúveis presentes nas polpas de abacate, resultados em $\mathrm{g}$ de óleo/g de polpa seca*

\begin{tabular}{llcccc}
\hline RSL & $\mathrm{T}\left({ }^{\circ} \mathrm{C}\right)$ & Etanol & Hexano & Isopropanol & Acetona \\
\hline \multirow{3}{*}{$1: 5$} & 35 & $0,289 \pm 0,005$ & $0,454 \pm 0,003$ & $0,424 \pm 0,008$ & $0,445 \pm 0,008$ \\
& 45 & $0,305 \pm 0,064$ & $0,452 \pm 0,003$ & $0,449 \pm 0,008$ & $0,450 \pm 0,023$ \\
& 55 & $0,422 \pm 0,015$ & $0,535 \pm 0,004$ & $0,546 \pm 0,052$ & $0,557 \pm 0,046$ \\
$1: 7,5$ & 35 & $0,365 \pm 0,005$ & $0,462 \pm 0,005$ & $0,478 \pm 0,004$ & $0,478 \pm 0,001$ \\
& 45 & $0,378 \pm 0,099$ & $0,541 \pm 0,009$ & $0,549 \pm 0,002$ & $0,535 \pm 0,092$ \\
& 55 & $0,458 \pm 0,015$ & $0,535 \pm 0,003$ & $0,55 \pm 0,001$ & $0,548 \pm 0,015$ \\
$1: 10$ & 35 & $0,481 \pm 0,011$ & $0,439 \pm 0,015$ & $0,468 \pm 0,006$ & $0,484 \pm 0,007$ \\
& 45 & $0,577 \pm 0,003$ & $0,552 \pm 0,002$ & $0,561 \pm 0,003$ & $0,566 \pm 0,014$ \\
& 55 & $0,574 \pm 0,006$ & $0,550 \pm 0,002$ & $0,553 \pm 0,021$ & $0,565 \pm 0,005$ \\
\hline
\end{tabular}

*Resultados expressos pela média e desvio padrão.

extraído também aumentou, o mesmo é notado com relação as diluições do solvente. Observa-se também que na diluição $1: 10$, na temperatura de $55^{\circ} \mathrm{C}$ todos os solventes extraíram elevadas quantidades de óleo da polpa do abacate. Ao utilizar maiores diluições e temperaturas, o etanol mostra-se viável para extração de óleos vegetais. De acordo com Sawada (2012) o etanol mostra potencial para substituir o hexano, pois além de não gerar resíduos tóxicos, não é prejudicial a saúde humana.

Almeida et al. (2017), em um estudo sobre a extração do óleo de Moringa utilizando diferentes solventes, entre eles acetona e hexano, observaram que em todos os tempos analisados, o hexano extraiu maior quantidade de óleo $\mathrm{O}$ mesmo não foi observado neste trabalho para as extrações de óleo de polpa de abacate.

Gandhi et al. (2003), buscaram diversos solventes para extração de óleo de soja, desta forma, utilizaram os solventes puros n-hexano, n-heptano, n-propanol, isopropanol e etanol, além da aplicação de sistemas de solventes aquosos (90:10 n-propanol) e azeótropos como, por exemplo, n-hexano + isopropanol $(78+22)$, em períodos de extração crescentes até $10 \mathrm{~h}$. Desta maneira, concluíram, ao se comparar com o n-hexano, n-heptano, n-propanol, isopropanol e etanol foram efetivos na extração de forma igual, o que é notado neste experimento visto que na proporção $1: 10$ a $55^{\circ} \mathrm{C}$ todos os solventes foram efetivos na extração do óleo da polpa do abacate.

\section{CONCLUSÕES}

Os aumentos de temperatura e das diluições favoreceram o aumento da extração de óleo da polpa de abacate. $\mathrm{O}$ etanol apresentou baixo rendimento na diluição $1: 5$ a $35^{\circ} \mathrm{C}$. $\mathrm{Na}$ diluição $1: 10$ a $55^{\circ} \mathrm{C}$ todos os solventes extraíram quantidades de óleo semelhantes.

Através dos resultados pode-se concluir que o etanol pode ser considerado um solvente alternativo para extração de óleos vegetais devido a sua utilização agrícola e alta produtividade.

\section{AGRADECIMENTOS}

CNPq/PIBIC que possibilitaram a realização deste trabalho. 


\section{REFERENCIAS}

ALMEIDA et al. Extração do óleo de Moringa por diferentes métodos, visando a produção de biodiesel. In: I Congresso Nacional de Engenharia de Petróleo Gás Natural e Biocombustíveis. Anais Eletrônicos. Disponível em: <http://www.editorarealize.com.br/revistas/conepetro/trabalhos/Modalidade_4datahora_ 30_03_2015_20_28_58_idinscrito_1032_232d183e402582e8b9f8a4cd44ef2a65.pdf> Acesso em 25 de março de 2017.

BAKER, E. C.; SULLIVAN, D. A. Development of a pilot-plant process for the extraction of soy flakes with aqueous isopropyl-alcohol. Journal of the American Oil Chemists Society, v. 60, n. 7, p. 1271-1277, 1983.

DAGOSTIN, J. L. A. et al. Liquid-liquid phase equilibrium measurements and modeling for systems involving \{soybean oil plus ethyl esters plus (ethanol plus water)\}. Fuel, v. 141, p. 164-172, 2015.

DAGOSTIN, J. L.; CARPINE, D.; CORAZZA, M. L. Extraction of soybean oil using ethanol and mixtures with alkyl esters (biodiesel) as co-solvent: kinetics and thermodynamics. Industrial Crops and Products, v. 74, p. 69-75, 2015.

FONSECA, H.; REGINATO-DARCE, M. A. B. Aflatoxin removal of peanut meals with aqueous ethanol. Sientia Agrícola, v.50, p. 154-156. 1993.

GANDHI, A. P. et al. Studies on alternative solvents for the extraction of oil-I soybean. International Journal of Food Science and Technology, v. 38, n. 3, p. 369-375, 2003.

JORGE, T. D. S. et al. Physicochemical And Rheological Characterization Of Avocado Oils. Ciencia e Agrotecnologia, v. 39, n. 4, p. 390-400, 2015.

LIAUW, M. Y. et al. Extraction of nem oil (Azadirachta indica A. Juss) using n-hexane and etanol: studies of oil quality, kinetic and thermodynamica. Journal of Engineering and Applied Sciences, v. 3, n. 3, p. 49-54, 2008.

OLIVEIRA, R. et al. Effects of the extraction conditions on the yield and composition of rice bran oil extracted with ethanol-A response surface approach. Food and Bioproducts Processing, v. 90, n. 1, p. 22-31, 2012.

RODRIGUES, C. E. C.; ARACAVA, K. K.; ABREU, F. N. Thermodynamic and statistical analysis of soybean oil extraction process using renewable solvent. International Journal of Food Science and Technology, v. 45, n. 11, p. 2407-2414, 2010.

SANTOS, M. A. Z. et al. Profile of Bioactive Compounds in Avocado Pulp Oil: Influence of the Drying Processes and Extraction Methods. Journal of the American Oil Chemists Society, v. 91, n. 1, p. 19-27, 2014.

SAWADA, M.M., Estudo da viabilidade técnica da substituição de hexano por etanol no processo de extração de óleo de soja: cinética de extração e índices de qualidade. Dissertação (Mestrado em Ciências da Engenharia de Alimentos). Universidade de São Paulo, p. 129.

TANGO, J.S.; CARVALHO, C.R.L.; SOARES, N.B. Caracterização física e química de frutos de abacate visando o seu potencial extração de óleo. Revista Brasileira de Fruticultura, v.17, n.1, p.17-23, 2004.

TANGO, J.S.; TURATTI, J.M. Óleo de abacate. In: ABACATE-cultura, matéria-prima, processamento e aspectos econômicos. p. 156-192. 1992.

TIR, R.; DUTTA, P. C.; AHMED, B. H A. Y. Effect of the extraction solvent polarity on the sesame seeds oil composition. European Journal of Lipid Science and Technology, v. 114, n. 12, p. 1427-1438, 2012. 